\title{
La Casa Cielo: la connotación mágica del arquetipo doméstico prehispánico en el Valle de Aburrá*
}

\section{Resumen}

Con el deseo de aportar elementos de significación para la comprensión del desarrollo del espacio doméstico, este artículo indaga por su condición en el contexto prehispánico delValle de Aburrá basándose en una adaptación del planteamiento que Régis Debray hace sobre el devenir de la imagen en Occidente identificando tres momentos que denomina la mirada mágica, la estética y la económica; se pone en evidencia que esta perspectiva también es aplicable a la construcción mental que el ser humano crea sobre la arquitectura y, en particular, se muestra que la cabaña amerindia aburrá corresponde a la mirada mágica y que ella se estructuraba simbólicamente de manera vertical.
Juan David Chávez Giraldo. Doctor en Artes. Profesor Titular Universidad Nacional de Colombia. Medellín, Colombia. Correo electrónico: jdchavez@unal.edu.co

Recibido: Agosto 2014 Aprobado: Abril 2015

Palabras clave:

Arquitectura prehispánica, espacio doméstico, hábitat, mirada mágica, Valle de Aburrá.

\footnotetext{
* Este artículo es la síntesis del primer capítulo de la investigación "Casa, Hogar y Cielo", que el autor realizó como tesis doctoral en Artes en la Universidad de Antioquia, cuya idea central versa sobre la pérdida contemporánea de la verticalidad en el espacio doméstico del Valle de Aburrá.
}

Revista KEPES Año 12 No. 11 enero-junio 2015, págs. 35-58 ISSN: 1794-7111(Impreso) ISSN: 2462-8115 (En línea) DOI: 10.17151/kepes.2015.12.11.3 


\title{
The Sky at Home or the magical connotation of the Pre- hispanic domestic archetype in the Aburrá Valley
}

\begin{abstract}
With the desire to provide elements of significance for understanding the development of the domestic space, this article explores its condition in the prehispanic context of the Aburrá Valley based on an adaptation of Regis Debray's approach about the future of the image in the West identifying three moments he calls the magic look, the aesthetics look and the economic look.

It is evidenced that this approach also applies to the mental construction that humans make about architecture and, in particular, it is shown that the Aburrá Amerindian hut corresponds to the magic look and that it was symbolically structured in a vertical maner.
\end{abstract}

Key words:

Prehispanic Architecture, domestic space, hábitat, magical look, Aburrá Valley. 


\section{Introducción}

Un acercamiento a la historia general de la arquitectura doméstica en el Valle de Aburrá, permite verificar la existencia de tres tipos fundamentales que se asocian con la teoría que Régis Debray plantea para la historia de la imagen en Occidente (Debray, 1998, p. 39), según la cual existen tres miradas: la de carácter mágico, la de connotaciones estéticas y la que obedece a una concepción económica. Esta teoría permite además verificar una perspectiva universal en el proceso de desarrollo cultural del Valle de Aburrá, evidente en el espacio doméstico, y que alcanza siempre, aunque con cierto atraso temporal, el pulso global de la historia.

En el Valle de Aburrá la mirada mágica corresponde a la cabaña prehispánica, la estética se encarna en las casas de patios, y la económica se presenta en las torres de apartamentos. La investigación propone, que tanto en el tipo de la cabaña como en el de patios, se estableció una estructura simbólica de carácter vertical asociada al espacio geométrico, que se perdió con el tercer tipo. En este texto, en el que se aborda el hogar prehispánico como materialización de la mirada mágica y teniendo en cuenta que la urbanización del Valle ha destruido gran parte de los rastros arqueológicos, se verifica la existencia de la estructura vertical a partir de algunas evidencias arqueológicas, de asociaciones culturales ${ }^{1}$ y analogías etnográficas, de datos recogidos por tradición oral mediante entrevistas personales a indígenas de grupos culturales próximos a los que habitaron el Valle², de los estudios existentes sobre la arquitectura prehispánica, y de textos de la antropología filosófica³.

\footnotetext{
1 “[... la mayor parte de la cultura está hecha de rasgos que pertenecen en común a la humanidad o a un continente o, por lo menos, a toda una región y a numerosos grupos [...]" (Leroi-Gourhan, 1971, p. 271).

2 "[...] debemos considerar la posibilidad de que estas convergencias surjan, o bien porque la mente humana está 'predispuesta' a hacer sus obras de una sola manera (por ejemplo, creando opuestos binarios), o bien porque ciertos temas psicológicos profundamente asentados fueron establecidos en las culturas del Paleolítico superior en Asia y continuaron expresándose periódicamente en las tradiciones culturales posteriores de Asia y América" (Murillo, 2006, p. 387).

Como parte de la investigación se entrevistaron a Abadio Green S. (tule), Eduardo Peña (zenú), Eulalia Yagarí G. (embera chamí), Milton Santacruz A. (gunadule), William Carupia C. (embera eyabira), Gustavo Vélez T. (embera chamí), María Cerbelina Tintinago (yanacona) y Jair Zapata T. (arhuaco) entre 2008 y 2013.

${ }^{3}$ Ver bibliografía al final del artículo.
} 


\section{Contextualización general}

Hoy se puede afirmar que el hombre no es originario de América. "Los testimonios arqueológicos prueban que los primeros americanos eran de la especie Homo Sapiens, que apareció hace aproximadamente 50.000 años en el Viejo Mundo" (Aula Abierta, 1984, p. 6); en consecuencia, las migraciones que dieron origen al poblamiento del continente ${ }^{4}$, son el primer elemento que permite hacer comparaciones de patrones culturales verificables en contextos similares ya que los primeros pobladores del área colombiana llegaron hace unos 15.000 años del norte y del sur en pequeños grupos nómadas ${ }^{5}$, colonizando prácticamente todo el territorio en busca de alimento y abrigo, para lo cual utilizaron campamentos con materiales vegetales cerca de las fuentes de agua, acogiendo así el arquetipo ancestral ${ }^{6}$, que en principio fue colectivo y se estableció con ligeras variaciones en cada región.

Específicamente en el territorio antioqueño se instauró con el tiempo un Estado de ascendencia chibcha en el que convivían comunidades que adquirieron características tribales y luego de cacicazgos. Los hallazgos arqueológicos de mayor antigüedad en el Valle de Aburrá se descubrieron en el sitio La Morena, Envigado, donde se obtuvieron elementos líticos datados en el 10060 a.p. pertenecientes a grupos precerámicos (Santos, 2010, pp. 22-24).

Una segunda fase de desarrollo cultural entre el 7500 y el 5000 a.p., hace referencia a grupos que manipularon especies vegetales e instrumentos de piedra; según algunos hallazgos de estos estadios, en donde se evidenciaron huellas de enterramiento de postes, se puede deducir que sus abrigos pertenecían al tipo de la cabaña y que él se mantuvo por muchos siglos revelando secuencias de ocupación que inician desde el 10000 a.p. hasta el período de la Conquista española.

\footnotetext{
${ }^{4}$ Las teorías más aceptadas sobre el poblamiento de América son: el origen único a partir de una migración asiática (Hrdli ka); el origen múltiple de cuatro migraciones -australiana, malayo-polinesia, esquimal y asiática- (Rivet); el origen africano, poco aceptada; y el origen oceánico cuyo primordial poblamiento sería el polinesio.

${ }^{5}$ Según Cardich (2003, p. 474), "[...] eran portadores de patrones culturales correspondientes al Paleolítico Superior del Viejo Mundo con agregados de rasgos persistentes del Paleolítico Medio [...]".

${ }^{6}$ Entre los más antiguos hallazgos de este tipo de abrigos están los de Terra Amata (ca. 380000 a.p.) y Lazaret en Niza, y los de Baume-Bonne en Quinson.
} 


\section{El aspecto mágico del espacio doméstico de los aburráes}

De los más de 150 asentamientos paleoindios registrados en el Valle de Aburrá, algunos de los cuales se describen como densos y de gran tamaño, solo se tienen ciertos objetos de piedra que permiten plantear hipótesis de acuerdo con la idea universal de la condición doméstica, pues "La organización del espacio habitado no es solamente una comodidad técnica; es, al mismo título que el lenguaje, la expresión simbólica de un comportamiento globalmente humano" (Leroi-Gourhan; 1971, p. 311). No obstante, de los agroalfareros se tiene mayor cantidad de vestigios, lo cual facilita el análisis y la verificación de la hipótesis planteada en este artículo. Es así como la estructura territorial, los centros rituales, la ingeniería, la cerámica, los petroglifos y los megalitos, algunos de los cuales aún subsisten, permiten hablar del estado evolutivo de aquellos grupos; a lo que se suma la descripción de las crónicas de los conquistadores ibéricos?

En el Valle, se ha identificado una serie de asentamientos tempranos asociados a tecnologías simples con producción de alimentos y con modos de vida utilitaria y simbólica. Estos grupos, cuyas zonas de habitación se encontraban sobre colinas o sobre terraceos naturales o artificiales con características nucleadas en las partes bajas y dispersas en las laderas y partes altas ${ }^{8}$, tenían su espacio doméstico referido al sistema cósmico 9 . De otro lado, los hallazgos sugieren migraciones estacionales poniendo en evidencia el afán humano de dominar racionalmente el medio en el que habita, pues "[...] los fenómenos de inserción espaciotemporal [...] corresponden a una verdadera toma de posesión del tiempo y del espacio a través de símbolos, a una domesticación en el sentido más estricto, puesto que terminan en la creación, en la casa, y más allá de la casa, de un espacio y un tiempo domesticables" (Leroi-Gourhan, 1971, p. 305), así, el mundo se aprehendía para recibir el devenir cíclico e instaurar un orden humano. Como se representa en la Figura

\footnotetext{
Al respecto puede verse: Gutiérrez (1985), Tovar (1993) y Escobar (2003).

${ }^{8}$ La evidencia de este patrón está registrada en los estudios y prospecciones arqueológicas realizadas en el Valle de Aburrá y citadas en la bibliografía de este artículo.

${ }^{9}$ Los asentamientos de los pueblos primitivos, así como sus componentes (templos, viviendas, graneros, caminos, megalitos y sitios rituales) están ubicados en correspondencia con los puntos y las líneas astrales.
} 
1, la casa era el centro dimensional tempo-espacial del universo prehispánico, confirmando que:

Este punto sobre el plano horizontal de la superficie terráquea se convirtió, ampliándose, en el eje del mundo, que se levantaba verticalmente sobre el punto central. Aunque en forma muy variada, el principio es típico y permanente. El eje une los tres campos del espacio, separados por una articulación vertical: el mundo de lo sobre-terreno, de lo infra-terreno y de lo terreno-humano. (Bollnow, 1964, p. 458)

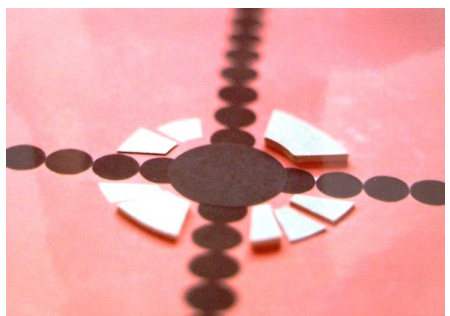

Figura 1. La casa como centro del universo. Modelo tridimensional y fotografía: J. D. Chávez C.

Estos agroalfareros tempranos ocuparon casi todos los rincones del Valle y aunque no está todavía claro si el grupo denominado Marrón Inciso o Pueblo Viejo desplazó a otro conocido como de Ferrería, o si ambos convivieron, o hubo un desplazamiento gradual o si era un mismo grupo con dos estilos cerámicos, lo cierto es que en numerosas oportunidades se encuentran vestigios de ambos estilos en los mismos lugares de vivienda, recreando en las diferentes fases de asiento, el espacio doméstico de manera palimséstica ${ }^{10}$, corroborando el mito del eterno retorno que explica que "[...] el hombre arcaico, no conoce ningún acto que no haya sido planteado y vivido anteriormente por otro, otro que no era un hombre. Lo que él hace, ya se hizo. Su vida es la repetición ininterrumpida de gestos inaugurados por otros" (Eliade, 1972, p. 15), lo cual remite a la conexión temporal de pasado, presente y futuro a través de la arquitectura; así la casa era lugar de confluencia de un tiempo eterno.

${ }^{10}$ Para Santos y Otero (1996, p. 8), "[...], en las terrazas tempranas las huellas de postes halladas en las excavaciones muestran la presencia de una sola vivienda prehispánica, lo cual hace más aceptable la hipótesis de integración de estos grupos". 
En otro sentido, los hallazgos dejan ver que estos nativos enterraban a sus muertos incinerados en urnas cerámicas depositadas en pozos en el área de sus viviendas y acompañaban los restos con vasijas, husos y objetos de orfebrería; de lo cual se deduce que entendían la vida como preparación para la muerte y afirmaban su espacio real cotidiano en el virtual del más allá.

Algunos volantes de huso hallados en estas tumbas-vivienda parecen reflejar, por sus formas cónicas y los motivos de líneas incisas, la forma y estructura de las cámaras funerarias. Esto es posible ya que el modelo del universo puede reproducirse indefinidamente a distintas escalas y en múltiples espacios y objetos. (Santos, 1995, p. 43)

Este sistema fractal de pensamiento a diversos niveles, se refleja en la concepción de la casa y por lo tanto imprime al espacio doméstico idéntica concepción cosmológica; en el volante de huso de la Figura 2 se puede apreciar la abstracción de esta estructura conceptual del mundo. Adicional a esto, la proyección animista del universo mítico prehispánico llevó a dividir el mundo en dos realidades, la asociada al cuerpo físico y la relativa a lo espiritual; por ello, los enterramientos fundan el sentido trascendente del espacio doméstico hacia esa dimensión eterna, adoptando la misma dualidad y convirtiéndose en receptáculo de las dos realidades.

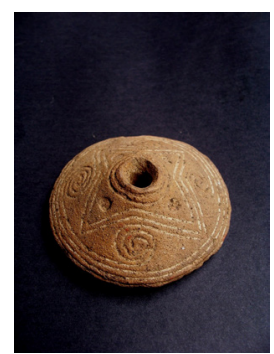

Figura 2. La multiescalaridad simbólica: volante de huso. Fotografía: J. D. Chávez G. 
Esta condición simbólica se aprecia también en los centros rituales ${ }^{11}$ que tenían una configuración radial, demostrando que "El uso del círculo como motivo central se encuentra repetidamente en los rituales sagrados [...] suministrando un centro de seguridad y tranquilidad [...]" (Roose-Evans, 1995, p. 76), pero en estos casos, no aparece tan solo el círculo, sino que hace presencia la espiral como figura más compleja que representa la irrupción de varias dimensiones ${ }^{12}$, estableciendo vínculos temporales en un escenario que permite cruzar un umbral para acceder al mundo sagrado. Esto se constata en los sitios de carácter ceremonial, como Corrales (ver Figura 3), La Aldea (ver Figura 4) y el cerro Pan de Azúcar (ver Figura 5), donde se instaura un medio cósmico que permite avistar con cierta particularidad fenómenos celestes (Mejía, 2005, pp. 33-40). Lo que en última instancia permite plantear esta connotación mágico ritual del hábitat, es el establecimiento de un universo de similares características al tangible, que supera cualquier límite y se implanta en la cotidianidad, incluyendo la doméstica.

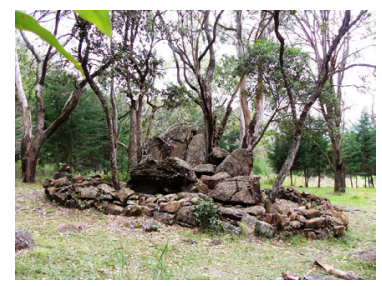

Figura 3. La magia multidimensional de la espiral: centro ceremonial de Corrales, municipio de Bello. Fotografía: J. D. Chávez G.

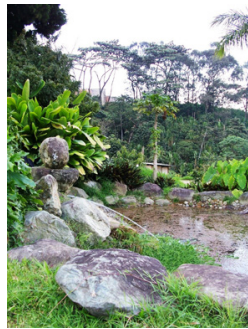

Figura 4. Centro ceremonial de La Aldea, municipio de La Estrella. Fotografía: J. D. Chávez C.

${ }^{11}$ De algunos se conservan rastros por su alta ubicación geográfica sin urbanización. Los más significativos son: Corrales (Bello), La Aldea (La Estrella) y el cerro Pan de Azúcar (Medellín).

${ }^{12}$ La espiral resulta cuando los fenómenos de rotación se unen con los de dilatación o contracción, y teniendo en cuenta que según C. Walsh (citado por Roose-Evans, 1995, p. 88): "[...] los símbolos le hablan a nuestra personalidad completa, no solo a nuestros oídos e inteligencias, crean resonancias y asociaciones inaccesibles a las palabras, apelan a la intuición y la experiencia tanto como al entendimiento. Y su poder es inconmensurablemente mayor que el de cualquier palabra", puede explicarse que la espiral (figura sin límites, abierta a lo infinito, macro y microscópicamente), represente los ciclos naturales como el de nacer, morir y resucitar, así como la dinámica entre lo material, humano e inferior y lo espiritual, divino y superior. 


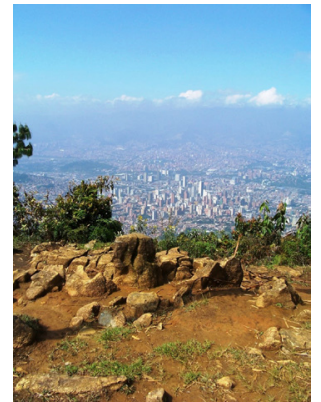

Figura 5. Centro ceremonial del cerro Pan de Azúcar, municipio de Medellín. Fotografía: J. D. Chávez G.

En esta domesticidad, las terrazas de piedra se construyeron para cultivos o para albergar a una o varias viviendas, la mayoría tenían forma circular u orgánica ${ }^{13}$ y poseían connotaciones religiosas representando el universo bajo el simbolismo del círculo $^{14}$, que define un centro cósmico ${ }^{15}$, para otorgarle así a la cabaña el carácter de puerta, donde se encuentran el cielo y la tierra, pues "Para entonces, el mundo es una bóveda celeste unida a la Tierra por una red de correspondencias ilimitadas [...]" (Leroi-Gourhan, 1971, p. 208) que requieren un umbral de paso, dado que:

Un ritual es como una puerta en una pared que nos conduce a un jardín secreto. [...] a otro espacio y otro tiempo [...] Pero también tenemos que salir de ese jardín, de modo que tiene que haber una puerta que nos permita hacerlo, para poder regresar al mundo corriente. (Roose-Evans, 1995, p. 76)

De acuerdo con los resultados de las excavaciones ${ }^{16}$, las viviendas estaban ubicadas cerca de los cultivos, y cada grupo familiar poséa una serie de mundos domésticos conectados de manera virtual por el sentido de su posesión. La casa extendía así su galaxia por el territorio, y el espacio doméstico adquiría vínculos directos con la tierra; de esta manera cosmos, tierra, casa y cuerpo se entendían como un mismo sistema. Por eso la elección del lugar para la casa era una tarea en la que intervenía el grupo familiar convocando las fuerzas de la Tierra y la intercesión de los espíritus antepasados, "La toma de posesión del sitio es defini-

\footnotetext{
${ }^{13}$ Tal geometría es constatable en los hallazgos de las excavaciones arqueológicas y también en terrazas aun existentes y visibles en Corrales (Bello), en el cerro Pan de Azúcar y en la zona de la laguna de Guarne.

14 “[...] el mundo que nos rodea, civilizado por la mano del hombre, no adquiere más validez que la que debe al prototipo extraterrestre que le sirvió de modelo. El hombre construye según un arquetipo" (Eliade, 1972, p. 19).

${ }^{15} \mathrm{El}$ indígena y arquitecto Jair Zapata T., explica que "el espacio y el territorio indígenas son como un embrión que crece a partir de un ombligo; como centro, crea un mundo que conforma lo sagrado y lo real, y que comunica las distintas estructuras del espacio existencial" (Entrevista personal, septiembre 18 de 2008).

${ }^{16}$ Referidas en los informes que se citan en la bibliografía del artículo.
} 
da no solamente por elementos visibles, también por un ritual sacro, como si la elección fuera demandada por una presencia divina [...]" (Varini, s.f., p. 57), así se constituía un lugar seguro, un reducto de tranquilidad térrea conectado con la eternidad; en tanto recinto sagrado de protección, sus habitantes la entendían y la percibían como una prótesis defensora.

Ese espacio tridimensional daba soporte al universo espiritual que incorporaba en su consistencia la representatividad simbólica de punto de confluencia de seres mortales y eternos; una vez inaugurada la puerta dimensional en el ritual de construcción, quedaba establecida la condición ceremonial del microcosmos; "Al asegurar su transición [...] sirve de enlace. Esta función, Ilamada simbólica [...] no es propia de la imagen ni su única propiedad" (Debray, 1998, p. 41), y constituye para la cabaña primitiva prehispánica, su fundamento mágico.

De esta manera, la multidimensionalidad de la cabaña radicaba en la organización del tiempo y el espacio desde un punto referencial del cual se desprendía todo el universo, material e inmaterial, ya que "El pensamiento de la antigüedad prealfabética es radiante como el cuerpo del erizo o de la estrella de mar" (Leroi-Gourhan, 1971, p. 208), por esta razón la choza era unitaria pero multidireccional, convergente y a la vez divergente; en ella surgían fuerzas centrípetas que transmutaban a centrífugas. De tal manera, la espiral, presente en los petroglifos, como se puede observar en la Figura 6, en sus disposiciones megalíticas, en los volantes de huso y en las líneas dibujadas en la cubierta de las tumbas que reproducían las casas, es la figura geométrica que más se acerca a la experiencia existencial vivida en el bohío prehispánico ${ }^{17}$ : la expansión trascendente del ser y simultáneamente la concentración íntima del individuo ${ }^{18}$, con la casa como centro de tal dinámica. Esto es observable igualmente en los dibujos del indígena y arquitecto arhuaco Jair Zapata T. que explican de manera abstracta los mundos de su universo (Zapata, 2010, pp. 28-29, 33, 73, 75), al igual que en los dibujos de la Figura 7 del indígena tule Abadio Green S. que dejan ver también el carácter simbólico interdimensional de la espiral.

\footnotetext{
${ }^{17}$ Según Arcila (1977, p. 24), en las espirales de los petroglifos aburráes, que no son exclusivas de este contexto, "[...] no hubo la determinación de individualizar un motivo, o mejor, definir un tema, sino la de establecer la configuración armónica de las líneas como expresión simbólica de un mensaje, o por lo menos, la expresión de una emoción estética".

${ }^{18}$ Para Jung (1990, p. 17), "[...] procediendo de una época y de una civilización donde mucho ha no había ruedas aún, resulta solamente en parte de la experiencia externa; por la otra es un símbolo, una experiencia de dentro [...]".
} 


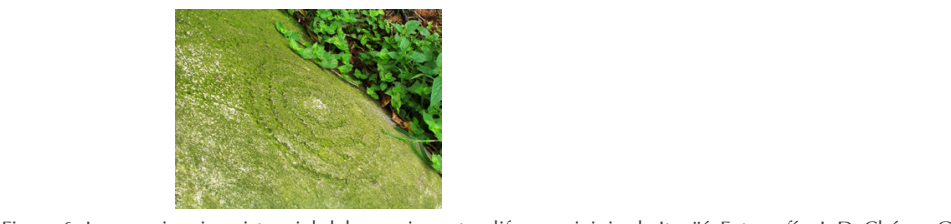

Figura 6. La experiencia existencial del espacio: petroglifo, municipio de Itagüí. Fotografía: J. D. Chávez G.

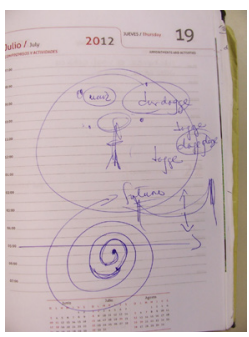

Figura 7. La condición simbólica interdimensional de la espiral. Dibujo: Abadio Green S.

Al respecto, cabe recordar que "En todos los grupos humanos conocidos, el hábitat responde a una triple necesidad: la de crear un medio técnicamente eficaz, la de asegurar un marco al sistema social y la de poner orden, a partir de allí, en el universo circundante" (Leroi-Gourhan, 1971, p. 311); en este último concepto ordenador, es que hace presencia la espiral y su sentido conector, al involucrar los distintos estratos que componen el universo indígena, pues ellos no están en el mismo plano sino que obedecen a una posición multidimensional accesible a través de una experiencia de doble dinámica, rotativa y expansiva, ordenadora "[...] del mundo de forma espiral al mismo tiempo que se integra lo vertical y lo horizontal" (Zapata, 2010, pp. 42-43), cuyo centro es la casa.

Esta dinámica se reproducía en diferentes aspectos; las analogías etnográficas permiten deducir que la orientación del acceso de las viviendas, por ejemplo, obedecía a un principio de orden universal ${ }^{19}$, en el que la casa se constituía en 
punto de convergencia entre dos ámbitos naturales: el agua y la tierra confluían en la casa y se ponía en evidencia de nuevo su papel como objeto conector. "En todos los relatos se encuentra el mundo al cual pertenecen los seres vivientes en una posición intermedia entre los dioses creadores -coincidente con el cielo- y la de los otros seres, a los cuales se accede por una quebrada o por debajo de la tierra [...]" (Varini, s.f., p. 55), en un gesto vertical, el artefacto habitacional era instrumento ceremonial para el encuentro del inframundo, de donde proviene el agua, con el supramundo, hábitat de las divinidades superiores; "[...] la casa se estructura en tres niveles [...] en sentido cosmogónico, simbolizan los tres mundos que conforman el Universo de la concepción indígena" (Rave, 2006, p. 44).

Se constata así la relación intrínseca entre la arquitectura y el sentido mágico de la reproducción abstracta de las condiciones del universo, "La casa cumple un papel de centro ordenador; es un reflejo del orden mayor [...]" (Rave, 2007-2008, p. 52) para dar albergue al recinto doméstico. Adjunto al espacio geométrico, se constituía un cosmos imaginario en el que divagaban seres de una dimensión mítica que hacía parte íntegra del espacio doméstico. El hogar era ordenador espectral del precepto superior para permitir la supervivencia de la carne y la presencia del alma en un ámbito complejo de realidades, signos y valores interconectados.

La cualidad simbólica del universo mitológico instaurado en la cabaña prehispánica, conlleva a una analogización del mundo en que se establece un ordenamiento sistémico que incluye al hombre, a los dioses y al cosmos. De acuerdo con Morín (1994, p. 175), esta situación desemboca en dos derivas culturales, la astrológica y la filosófica; la segunda a su vez obliga a una concepción de correspondencia entre el microcosmos y el macrocosmos que explica la versión hologramática de la imagen refleja del universo en la casa y viceversa. "El mundo de la forma se alimenta de las deidades y del inframundo para mantener el equilibrio natural" (Zapata, 2010, p. 24), de tal manera, el espacio era de carácter doble y en él se vivía con toda naturalidad la unidualidad. 
Ahora, según Read (1993), cuando el espacio se comprende como un vacío autónomo de extensión infinita y no como un conjunto de lugares, lo cual corresponde al estado de desarrollo cultural de los agroalfareros tempranos, se inicia un proceso de diferenciación entre contenido y contenedor que conlleva a su vez a la percepción consciente de la experiencia espacial estética. De tal suerte, aparece un sentido religioso trascendental, que ubica, separa y establece distancias entre mundos, seres, dioses y cosas; así es posible la instauración de un mediador, de un centro, un referente asociado a lo más próximo: el espacio doméstico.

En consecuencia y de acuerdo con la información recogida en la investigación, se materializaban cuatro estratos del huevo vital que a su vez reflejaban la concepción de mundos dentro de la cosmogonía de aquellos indígenas aburráe ${ }^{20}$. Así entonces aparecía el primer nivel de la parte inferior de la construcción constituida, o por los maderos estructurales que soportaban el piso o por la terraza de piedra; este nivel representaba la tierra de la cual se tomaba posesión temporal, así como la fuente de agua. Aislando funcionalmente la casa del suelo, de los animales y de los seres del inframundo, conectaba con la dimensión de los antepasados, que al morir y ser enterrados bajo la casa, se convertían en mensajeros celestes, protectores y anclas del sentido originario de la reproducción del ritual prototípico de la creación. Un segundo nivel estaba comprendido por el mundo de los humanos, que se concebía como el corazón de la casa, espacio del cuerpo material y lugar del fuego que otorgaba la connotación de hogar. Aquí se desarrollaba gran parte de la cotidianidad y al mismo tiempo era el lugar del descanso diurno y del sueño nocturno; simbólicamente era el punto de conexión entre la conciencia y el inconsciente, entre la vigilia de la razón y el mundo onírico; aquí se esperaban las tinieblas nocturnas al amparo de los dioses protectores y se recibían los primeros rayos de luz de la renovación cíclica de la vida, presente en el símbolo de la espiral.

La tercera franja de la casa se constituía en la concavidad de la cubierta donde se reproducía la imagen de la bóveda celeste asociada al mundo espiritual superior;

\footnotetext{
${ }^{20}$ Además de las fuentes bibliográficas consultadas y reseñadas en la bibliografía, se sostuvieron entrevistas personales y consultas por correo electrónico entre 2005 y 2013 con los investigadores Julia Rave A., Iván D. Vélez R., Santiago Ortiz A., Gabriel Monsalve, Edgar Bolívar R., Neyla Castillo E., Fernando Urbina R., John Botero S. y Pablo Aristizábal E., y con los indígenas ya mencionados, quienes confirman la hipótesis de los estratos en la casa ancestral indígena. Ver también Rave (2006, pp. 44-48). De igual manera, en los actuales tambos embera, se identifican los mismos cuatro niveles: deheru, deso, deburu y el de, ver Botero (2009, pp. 52-53).
} 
en ella se almacenaban utensilios, granos y objetos ceremoniales. Era el mundo de las cosas, de los objetos que representaban un valor simbólico; era el lugar en el que se concretaba el ser en el tiempo para dejar su huella, para perpetuarse en el horizonte de los años.

Y finalmente aparecía un cuarto nivel en la cumbre exterior de la cubierta ${ }^{21}$, en donde convergía la espiral microcósmica para conectarse con la espiral macrocósmica; que "comprende el crecimiento del Universo, relacionando nueve mundos, [...] que hacen parte de la integralidad terrenal. Por lo cual siempre se entiende la vivienda como útero, donde permanentemente se forma la vida a partir del espiral de la vida22", como ombligo del espacio doméstico, establecía la relación trascendental con las energías divinas y espirituales. Era el nudo final del tejido del hogar que cerraba el sistema físico para abrir el intangible. Estos cuatros niveles se pueden apreciar en la Figura 8, reproducción contemporánea de un bohío prehispánico en la urbanización La Aldea (La Estrella).

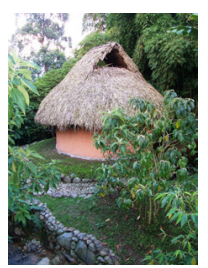

Figura 8. Estratos del espacio doméstico: reproducción contemporánea de la cabaña prehispánica, urbanización La Aldea, municipio de La Estrella. Fotografía: J. D. Chávez G.

La dimensión vertical representa tres niveles o mundos. El mundo de arriba o mundo celeste, el mundo del medio o mundo terrenal y el mundo de abajo o inframundo. Estos niveles cumplen funciones específicas y complementarias. Se encuentran interrelacionados e interconectados entre sí como unidad formal y espacial. El mundo terrenal define el hábitat de los seres humanos, y sobre él inciden el mundo celeste y el inframundo. (Zapata, 2010. p. 13)

\footnotetext{
${ }^{21}$ Resulta significativamente simbólico el hecho de que en las tumbas de pozo con cámara lateral excavadas por Santos en el cerro El Volador, que simulan las casas de los vivos, se encuentran representados los ápices superiores de la cubierta. Así también, en algunos bohíos embera actuales, y en algunas casas arhuacas, en la cumbre de la cubierta se ubican cuencos cerámicos y varas de madera de particular sentido cosmogónico.

${ }^{22}$ Indígena y arquitecto Jair Zapata, correo electrónico al autor, noviembre 13 de 2012.
} 
Es así como se constata "[...] una estructura universal que responde a la estructura del cosmos, y ambas al cuerpo humano que en última instancia es el referente a partir del cual se ordena el mundo"23.

\section{Conclusiones}

En la casa prehispánica se establecía pues una estructura espiral virtual simbólica articulando varios niveles dimensionales y haciendo las veces de ombligo astral, "[...] la espiral estaría separando varios niveles cósmicos, al mismo tiempo que uniéndolos, como un cordón umbilical [...]" (Santos, 1995, p. 42). La estructura virtual espiralada determinaba que más que una cosa, la cabaña era una operación y una ceremonia, estaba más próxima a la inmaterialidad simbólica que a la consistencia tangible. El esquema gráfico de la Figura 9 sintetiza tales conexiones convergentes para corroborar que "El símbolo es un objeto de convección que tiene como razón de ser el acuerdo de los espíritus y la reunión de los objetos" (Debray, 1998, p. 53).

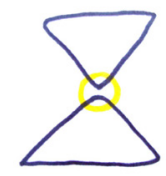

Figura 9. El ombligo cósmico, la versión mágica de la imagen. Esquema gráfico: J. D. Chávez G.

La choza primitiva aburrá obedece a un tipo universal, una suerte de impresión física de la imaginación perceptiva que se denomina engrama; la imagen que se ajusta a estos modelos es heredada naturalmente mediante una predisposición física, que constituye un arquetipo según Jung ${ }^{24}$ predisponiendo a la creación de figuras y objetos preestablecidos de manera ancestral. Estas características estructurales

${ }^{23}$ Neyla Castillo E., correo electrónico al autor, noviembre 26 de 2012.

${ }^{24}$ Ver Jung (1984, p. 261; 1990, p. 133; 1991, p. 53; 1994, pp. 11, 149, 166, 173) y Jung et al. (1969, pp. 67, 79) 
de la mente humana son el resultado de experiencias vitales de gran impacto y repetidas sistemáticamente durante millones de años de manera colectiva.

Para finalizar, debe hacerse alusión a los cambios identificados a partir del siglo IX d.C., pues aunque los asentamientos seguían siendo dispersos y con las pautas de ocupación anteriores, los cementerios se separaron de las viviendas y la especialización del espacio doméstico había iniciado un proceso de independización de recintos y de establecimiento de una constelación de edificaciones anexas a un núcleo principal, que cambió en planta por una elipse, lo cual respondía a una complejización de las actividades y a la aparición de zonas específicas.

El hábitat básico había pues desplegado un proceso de evolución en el que aquel espacio espiralado, interconectado con los dos campos complementarios de la naturaleza humana, daba paso a un microcosmos en el que lo práctico cobraba mayor importancia. De todas formas y a pesar de aquellos cambios, la choza seguía encarnando la mirada mágica de la cual habla Debray, en la que la condición mental que se proyectaba sobre la realidad material de aquel universo doméstico la convertía en "Conmutador del cielo y la tierra, intermediario entre el hombre y sus dioses" (Debray, 1998, p. 41).

\section{Referencias}

Acevedo, J. L. (2003). Aldea y sistema de canales del siglo III d.C. en el Valle de Aburrá. Plan de manejo arqueológico El Ranchito, predios de Sur S.A. Medellín, (doc. electrónico inédito).

Alzate, N., \& Osorio, C. J. (2009). Aproximación a una contextualización histórica y cultural de los petroglifos del Valle de Aburrá. Trabajo de grado. Antropología, Universidad de Antioquia, Medellín (doc. electrónico inédito). 
Arango, S. (1989). Historia de la arquitectura en Colombia. Bogotá: Universidad Nacional.

Arcila, G. (1977). Introducción a la arqueología del Valle de Aburrá. Medellín: Universidad de Antioquia. . (1996). Memorias de un origen. Medellín: Universidad de Antioquia.

Aristizábal, P. (2011). Programa de arqueología preventiva puente de la calle 4 sur, Medellín. Informe final. Medellín: Consorcio puente calle 4 sur / Obras Públicas / Alcaldía de Medellín, (doc. electrónico inédito).

Aula Abierta, Equipo Editorial. (1984). Culturas indígenas americanas. Barcelona: Salvat.

Bollnow, O. F. (1964). El hombre y su casa. Revista Eco, 52-54, 452-493.

Botero, J. (2009). Del tambo a la vivienda seriada. Monografía de grado de la Especialización en Planeación Urbano Regional. Facultad de Arquitectura, Universidad Nacional. Medellín, (doc. inédito).

Botero, S. (1999). Gente antigua, piedras blancas, campos circundados. Vestigios arqueológicos en el altiplano de Santa Elena (Antioquia - Colombia). Boletín de Antropología, Medellín, 13(30).

Botero, S., \& Vélez, N. (1997). Piedras Blancas: transformación y construcción del espacio. Investigación arqueológica en la cuenca alta de la quebrada Piedras Blancas. Informe de prospección. Boletín de Antropología, Medellín, 11(27). 
Cardich, A. (2003). Hacia una prehistoria de Sudamérica. Culturas tempranas de los Andes Centrales y de Patagonia. Buenos Aires: Universidad de la Plata.

Cardona, L., \& Nieto, Luis. (2000). Transformaciones territoriales en los ecosistemas estratégicos del Valle de Aburrá. La cuchilla El Romeral. Prospección arqueológica. Medellín: Universidad de Antioquia / CORANTIOQUIA, (doc. inédito).

Cardona, L., Obregón, M., \& Castillo, M. (1999). Prospección arqueológica en el Cerro Pan de Azúcar. Medellín: Universidad de Antioquia / CORVIDE, (doc. inédito).

Cardona, L., Obregón, M., \& Castillo, H. (2000). Prospección arqueológica Cerro Pan de Azúcar. Medellín: Universidad de Antioquia/ CORVIDE, (doc. inédito).

Cassirer, E. (1975). El concepto de la forma simbólica en la constitución de las ciencias del espíritu. En: Esencia y efecto del concepto de símbolo. México: Fondo de Cultura Económica.

. (1976). Antropología filosófica. Introducción a una filosofía de la cultura. Bogotá: Fondo de Cultura Económica.

Castillo, N. (1996). Las culturas indígenas prehispánicas. En: Melo, J. O. (Ed.), Historia de Medellín, Tomo I. Bogotá: Compañía Suramericana de Seguros.

Castro, G. (1998). Prospección y valoración del patrimonio arqueológico en el Corregimiento de Pueblo Viejo, Municipio de La Estrella. Medellín: CORANTIOQUIA, (doc. inédito).

. (1999). Investigaciones arqueológicas en la cuenca alta de la Quebrada Piedras Blancas, Corregimiento de Santa Elena, Medellín. Medellín: CORANTIOQUIA, (doc. inédito). 
Debray, R. (1998). Vida y muerte de la imagen. Historia de la mirada en Occidente. Barcelona: Paidós.

Duque, F. (2008). Habitar la tierra. Madrid: Abarra.

Duque, J. P., Salazar, O., \& Castaño, G. E. (2004). Saminashi. Arquitectura y cosmogonía en la construcción kogui. Bogotá: Universidad Nacional de Colombia.

Eliade, M. (1972). El mito del eterno retorno. Arquetipos y repetición. Madrid: Alianza Emecé.

Escobar, M. (Comp.). (2003). La ciudad y sus cronistas. Medellín: Instituto Técnico Metropolitano.

Fiedel, S. J. (1996). Prehistoria de América. Barcelona: Grijalbo Mondadori.

Gutiérrez, F. (1985). América a través de sus códices y cronistas. Barcelona: Salvat.

Hildebrand, M. von. (1983). Vivienda indígena, Amazonas. Proa, 323, 12-21.

Hoyos, G. M., \& Molina, Á. M. Historia de Itagüí. (s.f.). Recuperado de http://tesis. udea.edu.co/dspace/bitstream/10495/223/1/Historialtagui.pdf

Jung, C. G. (1984). Simbología del espíritu. México: Fondo de cultura económica. . (1990). Formaciones de lo inconsciente. Barcelona: Paidós. . (1991). La interpretación de la naturaleza y la psique. Barcelona: Paidós. . (1994). Arquetipos e inconsciente colectivo. Barcelona: Paidós. 
Jung, C. G., et al. (1969). El hombre y sus símbolos. Madrid: Aguilar.

Langebaek, C. H., et al. (2002). Arqueología y guerra en el valle de Aburrá: estudio de cambios sociales en una región del noroccidente de Colombia. Bogotá: Uniandes.

Leroi-Gourhan, A. (1971). El gesto y la palabra. Caracas: Universidad Central de Venezuela.

Lévi-Strauss, C. (1976). Tristes trópicos. Buenos Aires: Universidad de Buenos Aires.

Martínez, L. E., et al. (2000). Territorios culturales, contextualización y ubicación de los asentamientos aburráes. Medellín: CORANTIOQUIA / Corporación GAIA, (doc. inédito).

Mejía, D. (2002). La entrevista. Recuperado de http://rupestreweb.tripod.com/ graciliano.html

Mejía, D. L. (2005). Metropolivisión, una revisión poética del valle de los aburráes en los albores del tercer milenio. Bogotá: Universidad Nacional de Colombia.

Morín, E. (1994). El método III. El conocimiento del conocimiento. Madrid: Cátedra.

Murillo, S. (2006). El mito de la vida privada. Madrid: Siglo XXI.

Nieto, L. E., Restrepo, A., \& Restrepo, J. C. (2003). Prospección arqueológica y plan de manejo en el área física donde se construirá el proyecto: Plan Parcial Pajarito. Medellín: EDU / Universidad de Antioquia, (doc. inédito). 
Obregón, M., Cardona, L. C., \& Gómez, L. I. (2003). Vivienda, producción minera y élites entre los siglos XVII y XIX en la cuenca alta de la quebrada El Rosario. Medellín: CORANTIOQUIA, (doc. inédito).

Piedrahita, J. (1975). Documentos y estudios para la historia de Medellín. Medellín: Consejo Municipal de Medellín.

. (1976). Del poblado de San Lorenzo a la parroquia del Poblado, 18761976. Medellín: Secretaría de Educación y Cultura del Departamento de Antioquia.

Politis, G. G. (1992). Los nukak: la arquitectura del nomadismo en la amazonía colombiana. Proa, 412, 11-20.

Prieto, E. (Dir.). (2005). Artes plásticas en Antioquia. Prehispánico - Colonia - Siglo XIX - Siglo XX. 10.000 años de arte [DVD multimedia]. Medellín: Fundación Víztaz / Gobernación de Antioquia / IDEA.

Rave, M. J. (2004-2005). Cultura y territorio amerindios, el caso del Valle de Aburrá, Colombia, Ilenando de significado el territorio. Libro dos. Medellín: Universidad Nacional de Colombia.

. (2006). La casa indígena en Colombia. Medellín: Universidad Nacional de Colombia / DIME.

. (2007-2008). Espacio y territorio sagrado. Lógica del ordenamiento territorial indígena. Libro tres. Medellín: Universidad Nacional de Colombia.

. (2010). Arquitectura prehispánica en el Valle de Aburrá. Medellín: Universidad Nacional. 
Read, H. (1993). Los símbolos de lo desconocido. En: Imagen e idea. México: Fondo de Cultura Económica.

Rendón, C. (1993). Nukak Maku: los últimos verdes [obra documental]. [1 videocasete: $52 \mathrm{~min}]$.

Roose-Evans, J. (1995). Ritos del alma. Bogotá: Tercer Mundo.

Rubio, G. A., \& Abdala, A. (s.f.). Atlas del hábitat en Colombia. Arquitectura indígena. Terrenos de la gran expedición humana, serie reportes de investigación $\mathrm{N}^{\circ}$ 7. Bogotá: Pontificia Universidad Javeriana.

Sánchez, E. (2001). Las culturas precolombinas de Colombia. En: Las culturas nativas. Los pueblos precolombinos. Barcelona: Océano.

Santos, G. (1995). El Volador: las viviendas de los muertos. Boletín de Antropología, Medellín, 9(25).

- (2006). Una tumba de cancel en el Valle de Aburrá, prospección y rescate arqueológico del área de la urbanización Álamos del Escobero. Envigado: Vértice Ingeniería / Secretaría de Educación para la Cultura del Municipio de Envigado, Sección Archivo Histórico, (doc. electrónico inédito).

. (2010). Diez mil años de ocupaciones humanas en Envigado [Antioquia]. El sitio La Morena. Envigado: Alcaldía de Envigado.

Santos, G., \& Otero, H. (1996). El Volador: una ventana al pasado del Valle de Aburrá. Medellín: Centro de Investigaciones Sociales de la Universidad de Antioquia, (doc. inédito). 
Sondereguer, C. (2007). Manual de estética precolombina. Tesis hermenéutica. Buenos Aires: Nobuko.

Tovar, H. (1993). Relaciones y visitas a los Andes. S. XVI. Bogotá: Colcultura / Biblioteca Nacional / Instituto de Cultura Hispánica.

Varini, C. (s.f.). Deara, una ruta de acercamiento al espacio y a la arquitectura de los indígenas emberá y waunana. Terrenos de la gran expedición humana. Bogotá: Pontificia Universidad Javeriana.

Vélez, N. (1999). El pueblo aburrá de Guayabal en 1541. Boletín de Antropología, Medellín, 13(30), 221-240.

Zambrano, F. (1992, 15 de octubre). Crónicas del Nuevo Mundo, Las ciudades en América. Fascículo 19. Medellín: El Colombiano / CINEP / Instituto Colombiano de Antropología.

Zapata T., J. (2010). Espacio y territorio sagrado. Lógica del ordenamiento territorial indígena. Medellín: Universidad Nacional.

Entrevistas y correos electrónicos al autor

Aristizábal E., Pablo, (antropólogo, Ph.D., investigador), correo electrónico noviembre 15 de 2012.

Bolívar R., Edgar, (antropólogo, profesor Universidad de Antioquia), correo electrónico noviembre 19 de 2012.

Botero S., John, (arquitecto, profesor Universidad Nacional), entrevista personal octubre 8 de 2010. 
Carupia C., William, (presidente OIA, indígena embera), entrevista personal enero 15 de 2013.

Castillo E., Neyla, (antropóloga, profesora Universidad de Antioquia), correo electrónico noviembre 6 de 2012.

Green S., Abadio, (profesor Universidad de Antioquia, indígena tule), entrevista personal noviembre 21 de 2012.

Monsalve, Gabriel, (antropólogo, miembro de la Fundación Aburrá), correo electrónico noviembre 22 de 2012.

Ortiz A., Santiago, (antropólogo, curador del Departamento de Antropología del Museo de la Universidad de Antioquia), entrevista personal febrero 18 de 2013.

Peña N., Eduardo, (indígena zenú), entrevista personal enero 16 de 2013.

Rave A., María J., (arquitecta, Ph.D., profesora Universidad Nacional), entrevistas personales junio 17 de 2005, agosto 22 de 2007.

Santacruz A., Milton, (indígena tule), entrevista personal enero 28 de 2013.

Tintinago, María C., (indígena tule), entrevista personal septiembre 8 de 2012.

Urbina R., Fernando, (filósofo, etnógrafo, profesor Universidad Nacional), correo electrónico noviembre 28 de 2012.

Vélez R., Iván Darío, (antropólogo, director de investigaciones y patrimonio de la Fundación Aburrá, consejero municipal de cultura), entrevista personal febrero 4 de 2010, correo electrónico noviembre 15 de 2012. 
Vélez T., Gustavo, (indígena embera), entrevista personal enero 28 de 2012.

Yagarí G., Eulalia, (exdiputada, indígena embera), entrevista personal enero 16 de 2013.

Zapata T., Jair O., (arquitecto, magíster en Planeación Urbano Regional, indígena arhuaco), entrevista personal septiembre 18 de 2008, correos electrónicos noviembre 13 y 21 de 2012.

Cómo citar este artículo:

Chávez, J. D. (2015). La Casa Cielo: la connotación mágica del arquetipo doméstico prehispánico en el Valle de Aburrá. Revista Kepes, 11, 35-59. 